\title{
ESSENTIAL COMPETENCIES FOR ENGINEERS FROM THE PERSPECTIVE OF FRESH GRADUATES
}

\author{
AKRAM SUlEIMAN* (i) JAFAR ABAHRE (i)
}

\begin{abstract}
A B S T R A C T
Determining the competencies required for engineering programmes has become important due to the increasing challenges faced by engineers after graduation and the tremendous development in technology. This research aims to identify the general competencies that fresh graduate students of engineering schools in Jordan believe they need to become competent and effective in their profession as engineers. This study was the first of its kind with students as respondents, and it was the first study of this kind in Jordan. Competencies were collected from a previous study with 48 competencies split into 11 groups. A questionnaire was prepared with these competencies, then rated for the degree of importance by answering "What engineering competencies graduates will require for their future work in Jordan?" The study showed that all competencies were vital, including technical, personal, nontechnical and attitudinal competencies. This study will help to link the outputs of university education provided by engineering departments with market needs as well as to harmonise study programmes offered by Jordanian universities. Also, the research outputs are expected to facilitate the transition process of students from one university to another. The empirically identified competencies could be used to help assess different engineering study programmes in Jordan.
\end{abstract}

KEY WORDS

engineering, Jordan, competencies, graduate, education

10.2478/emj-2020-0006 pages: $70-79$
Akram Suleiman

Al-Zaytoonah University of Jordan, Jordan ORCID 0000-0002-2665-1384

*Corresponding author: e-mail: a.suleiman@zuj.edu.jo

Jafar Abahre

An-Najah National University, Palestine ORCID 0000-0002-9307-859X

\section{INTRODUCTION}

The importance of this research comes from the fact that in Jordan, most engineering graduates become construction project leaders, e.g. project managers. Project managers play a major role in the failure or success of the construction industry business, and one way to improve the effectiveness of the construction industry is to improve the competencies of graduates from engineering study programmes. This would definitely contribute to nation-wide cost savings. For Jor-

Citation: Suleiman, A., \& Abahre, J. (2020). Essential competencies for engineers from the perspective of fresh graduates. Engineering Management in Production and Services, 12(1), 70-79. doi: 10.2478/emj-2020-0006 
dan to achieve advancement in the construction sector, competencies of these graduates must be determined and used so as to get the best result with fewer risks.

This study contributes to the worldwide picture of competencies required for engineers by complementing similar studies in Europe, Australia, and North America with a Jordanian viewpoint. The study is based on the perspective that an engineering programme evaluation should determine whether graduates have the competencies needed for their future work.

No similar study focusing on the competencies required by graduates of engineering study programmes has been previously conducted in Jordan. Also, it could not be assumed that results from other parts of the world could be generalised to Jordan. In general, this study provides results that could help to improve engineering education in Jordan.

The novelty of this research study comes from identifying generic engineering competencies that are perceived to be important by engineers across all disciplines, focusing on recent graduates. This study is the first of the kind conducted in Jordan and the Middle East. A relevant question for research and practice is, therefore, "What engineering competencies graduates will require for their future work in Jordan?"

Therefore, this study aimed to identify a concise list of competencies suitable for profiling the competencies of graduates from engineering study programmes then ranking these competencies according to the degree of importance.

\section{LITERATURE REVIEW}

The word "competent" comes from the word "competentia" in Latin. This term is defined as: "to struggle against another", and "to go hand in hand with someone or something" (Dante et al., 2012). Hornby and Thomas (1989) defined competency as "the knowledge, skills and qualities needed by effective managers" and pointed to "the ability to effectively perform the functions associated with management in a workplace.” Hogg (1993) explained that competencies were characteristics of a manager that guided the demonstration of skills and abilities that contributed to successful results within an occupational field. Kinkel et al. (2017) used the term competence to define the individual dispositional ability and readiness to act successfully and in a self-organised manner when facing novel, unstructured or complex situations or tasks and the ability to develop solutions for future situations.
Conceptual understanding and terminology related to generic competencies have varied, in particular at the higher education level (Solesvik, 2019; Mutiara et al., 2019; Šafránková \& Šikýřr, 2018). Billing (2003) researched standard graduate competencies required for jobs in various countries and found that skills can be exported to different countries. Barrie (2006) considered the definition of generic attributes for graduate students to be different within the same discipline and within the same institution. As in the US and Europe, several changes have occurred in Australia's engineering education in recent decades (Ferguson, 2006). Such changes have been generally determined by findings required for programme accreditation (Engineers Australia (EA) 2005a, 2005b, The Quality Assurance Agency (QAA) 2006, Accreditation Board for Engineering and Technology (ABET) 2008, European Network for Accreditation of Engineering Education (ENAEE) 2008). These require education to include non-technical content. The outcomes of the programmes specified by ABET, ENAEE and EA were similar, although they theoretically grouped outcomes differently. EA specified ten generic attributes, such as ABET's 11 programme outcomes. Nearly half of ABET and EA attributes were nontechnical. Five of ENAEE's six systems, by comparison, were mostly academic. But non-technical items recorded independently by EA and ABET were included in the transferable skills of the ENAEE outcome (ENAEE, 2008). Apart from work that aimed to set accreditation criteria, other important studies focused on various stakeholders. Research across a broader range of industries included SPINE: Successful Strategies of Global Engineering Education Benchmarking Review (Bodmer et al., 2002) for ten universities in Europe and the United States, a study conducted at the Royal Academy of Engineering in the United Kingdom (Spinks et al., 2006), a research conducted at Iowa State University (Brumm et al., 2006) and a survey at the University of Illinois (Meier et al., 2006).

The SPINE research interviewed academic staff, engineers with five to ten years of experience and directors of human resources (Bodmer et al., 2002). Data from 444 firms were obtained by UK research (Spinks et al., 2006). Together, the SPINE and the UK research looked at broad-level issues and concentrated on knowledge and skills while specifically addressing behaviour. Attitudes were protected against by the theoretical framework for the UK report. Iowa and Illinois research, on the other hand, considered attitudinal skills important. 
The Iowa research surveyed 212 participants, including clients, staff and graduates. In addition, 14 competencies were defined and extended to include 61 main actions. In the Illinois study, 415 institution managers ranked the importance of 54 skills.

According to Tucker and Cofsky (1994), competence may have five major components: experience refers to personal information, learning skills - to the person's ability to perform a specific task, self-concepts and values - to a person's behaviours, beliefs and selfimage - to physical characteristics, and clear reactions - to circumstances or data and ultimately to emotional impulses or related patterns that function promptly. Katz and Kahn (1966) divided competence into four areas of expertise: technical/functional (such as knowledge, attitudes and skills), management (such as knowledge and skills), human (knowledge, attitudes and skills), conceptual (capacity to imagine the unseen and to think, and use intuition in the planning of future businesses). Kinkel et al. (2017) described four clusters of competencies, namely, network competence, creative problem-solving competence, overview competence and integration competence that are crucial for the innovativeness of the value creation champions involved in the ChampNet project.

Osagie et al. (2016) stated studies that investigated individual competencies for corporate social responsibility (CSR), which were often conceptual in nature, and oriented towards educational programmes. But in the study, the authors performed a theoretical and empirical analysis of the individual CSR-related competencies needed by CSR professionals to contribute to achieving effective CSR implementation in a corporate context. The literature review complemented with interview data resulted in the eight distinct CSR-related competencies.

Budiman et al. (2020) stated that the Graduates Competency Standards (GCS) from the Bachelor of Education Programme in Indonesia were formulated in graduate learning outcomes which included: understanding competencies, educative learning competencies, mastery competence in the scientific field and/or expertise, and the competency for attitude and personality.

A framework that describes the competencies required for a specific job or organisation to achieve success is considered a model of competency. Depending on the working environment and structure, a group of maximum seven to nine competencies are normally required for a particular job and as shown in the competency model (Schippmann et al., 2000). Several models have been developed around the world for several jobs and organisations (Cheetham et al., 1996;
CIOB, 1996; McClelland, 1973; Boyatzis, 1982; Omran \& Suleiman, 2017).

The Definition and Selection of Competencies (DeSeCo) is a project that provided a rich theoretical framework for conceptual understanding (OECD, 2002). The skills indicated by the DeSeCo project could only be observed in real actions of an individual under specific situations. External criteria, capabilities and environments are all part of the complex essence of competencies (OECD, 2002). The framework defines competencies revealed in action as best evaluated through performance observations (Rychen \& Salganik, 2003). Consequently, the DeSeCo framework was consistent with frameworks assumed by other engineering study programme.

While large-scale studies on competencies required for engineers in the US and Europe were conducted, a large-scale study was necessary to verify whether the findings from the US and European research were applicable in Jordan.

\section{METHOD}

The design of this research was based on the study by Male et al. (2011). According to them, the DeSeCo framework was used for their study because its perspective was interdisciplinary, international and recognised the complexities of competencies (Male et al., 2011). From the DeSeCo framework, four complexities were particularly important to their research plan, namely, the following statements:

- Competencies are not independent but interrelated;

- A context is deemed relevant to the value of competencies;

- The stakeholder selection has an impact on competence selection;

- The outcomes of selected competencies affect the selection of competencies.

Without the existing literature, it would have been necessary to use a qualitative approach to discover and explain competencies that could be important. Instead and based on the above reasons, competencies were adopted from Male et al. (2011). The competencies have been developed into a list and validated as relevant using a questionnaire survey.

Therefore, this study mainly aims to identify competencies perceived as important by "fresh engineering graduates" to perform their work or tasks in the future. Besides competence ratings, the survey gathered personal data of respondents. 
To ensure that each competence is most closely related to the variable it represented, the exploratory factor analysis was demonstrated on competency items. Any item with factor loadings lower than 0.4 was removed from the analysis. The extracted 11 factors clarified 50 per cent of the variance of the retained 49 competence items (Male et al., 2011). Conceptually, the factor was named after the items that represented it. The competencies were grouped into 11 groups, as shown in Table 1.

A pilot study was conducted to eliminate potential misunderstandings and contradictions from the questionnaire and enhance its format, statement structure and the overall content. Some terms have been updated based on the feedback, competency items have been improved to be clear and concise, and competencies have been refined to a list of 48 items.

This research was unique because it challenged fresh graduates to consider their specific job criteria instead of rating competencies important to a group of experienced engineers. While referring to expertise, this study asked fresh graduates to answer the question "How important is each of the following competencies to do the job well?" ( $1=$ unnecessary; $5=$ critical). The questionnaire was translated from English into Arabic, to help respondents to understand the questionnaire more clearly as some did not have a good command of English. It took the participants an average of fewer than five minutes to complete it. The survey was carried out face-to-face for the convenience of the respondent.
According to the Ministry of Higher Education \& Scientific Research (2019), there are ten public and 17 private universities in Jordan, 12 located in the capital Amman, which offer an engineering degree. These 12 universities were involved in this research survey. In 2018, more than 10000 fresh engineering graduates were registered in the Jordanian Engineers Association - the target group of this study.

Based on the following equations, the relative sample was calculated (Barlett et al., 2001):

$$
N o=\left(\mathrm{t}^{2} * s^{2}\right) /\left(d^{2}\right)
$$

Where $\mathrm{t}=$ the value of the chosen a level of $0.025 \mathrm{in}$ each tai=1.96; $\mathrm{d}=$ acceptable margin of error for the mean being estimated $=0.15$; $s=$ the estimate of a standard deviation in the population $=1.25 ; \mathrm{N} 0=266$. The correction shall be done using the following formula:

$$
N=N o /\left[1+\left(\frac{N o}{p o p}\right)\right]
$$

Taking the population $=10000, \mathrm{No}=266$, so $\mathrm{N}$ becomes $=259$. A simple random sampling was adopted, which represented the engineering schools in Amman, Jordan. In total, 259 questionnaires were distributed, and 204 questionnaires were completed and returned by fresh engineering graduates yielding a response rate of 79 per cent. The Statistical Package for Social Sciences (SPSS) Version 18.0, and Microsoft Excel 2016 were used to analyse the data. To rank the competencies within each group, the relative importance index RII was used.

Tab. 1. Competency factors and their reflecting items

\begin{tabular}{|l|l|}
\hline \multicolumn{1}{|c|}{ COMPETENCY FACTOR } & \multicolumn{1}{|c|}{ COMPETENCY ITEMS THAT REFLECT THE COMPETENCY FACTOR } \\
\hline Communication & Written communication, verbal communication, English, graphical communication \\
\hline Working in diverse teams & Teamwork, interdisciplinary skills, diversity skills \\
\hline Self-management & Info-management, managing development, self-management, managing communication \\
\hline Professionalism & Demeanour, concern for others, honesty, commitment, self-motivation, loyalty \\
\hline Creativity/Problem-solving & Embracing change, creativity, sourcing info, problem-solving, systems, critical thinking \\
\hline Management/Leadership & $\begin{array}{l}\text { Coordinating, leading, supervising, risk-taking, managing, meeting skills, focus, workplace politics, } \\
\text { decision-making }\end{array}$ \\
\hline Engineering business & Cross-function familiarity, liability \\
\hline Practical engineering & Reliability, manufacturability, maintainability, integrated design \\
\hline Innovation & Marketing, entrepreneurship, networking \\
\hline Contextual responsibilities & Sustainability, social context, safety, community \\
\hline Applying technical theory & Research, theory, modelling, 3D skills \\
\hline
\end{tabular}




\section{RESULTS AND DISCUSSION}

\subsection{DemographiC RESUltS}

In total, 204 valid completed questionnaires were collected. The majority (88\%) of respondents were of the Jordanian nationality; all of them were aged between $21-30$, and $18 \%$ were females. These results were expected as most students in the Jordanian universities are of the Jordanian nationality, and they spend four years in the engineering school after finishing a high school at the age of 17. Based on the results, the engineering education could be described as a male-dominated sector. So, the study results could be generalised to males as more than $82 \%$ of students in the engineering schools are males.

\subsection{RANKING AND RII FOR COMPETENCIES}

This section aims to rate the value of the competency elements by their degree of relevance. The RII is a simple but effective approach that has been widely used to determine attitudes to the factors being assessed. Respondents were asked to rate competencies on a 5 -point Likert scale ( 1 for not important to 5 very important). In Tables 2 through 12, the RII was estimated based on the survey response.

\section{COMMUNICATION GROUP}

The communication group has four competencies which are English language, written, graphical, and verbal communication. The RII was used to rank the degree of importance of these competencies according to respondents. The results are shown in Table 2. The results indicated that the most important competency in the communication group was the English language with $0.923 \mathrm{RII}$, followed by written and verbal communication with 0.892 and 0.881 RII indices, respectively. The lowest important communication competency is the graphical communication competency with 0.881 RII. As Table 2 demonstrates, all competencies in the communication group are very important to engineers, with English being on top of the list as expected. Male et al. (2011) found that communication was the most important competence required by engineers in Australia. Also, Meier et al. (2000) included five highly important competencies in the communication group. In the UK, Spinks et al. (2006) showed that communication skills were considered important by the largest proportion of each cohort population. The results were consistent with a previous study made in the US (Brumm et al., 2006), which included the communication competency in the proposed Iowa State University (ISU) workplace competencies.

Tab. 2. Ranking and RII for the communication group competency

\begin{tabular}{|l|c|c|}
\hline \multicolumn{1}{|c|}{ COMPETENCIES } & RII & RANK \\
\hline English language & 0.923 & 1 \\
\hline Written communication & 0.892 & 2 \\
\hline Verbal communication & 0.881 & 3 \\
\hline Graphical communication & 0.812 & 4 \\
\hline
\end{tabular}

\section{WORKING IN A DIVERSE TEAM}

Working in a diverse team requires three competencies, namely, teamwork, interdisciplinary skills, and diversity skills. Table 3 shows the results of the survey in this respect, demonstrating that the most important competency for working in a diverse team is teamwork with 0.0.871 RII, followed by interdisciplinary skills with 0.783 RII. The least important competency in this group is the diversity skills competency with 0.77 RII. The results are consistent with previous studies conducted in Australia (Male et al., 2011) and in the US (Brumm et al., 2006), which included the team wok competency in the proposed Iowa State University (ISU) workplace competencies.

Tab. 3. Ranking and RII for working in a diverse team

\begin{tabular}{|l|c|c|}
\hline \multicolumn{1}{|c|}{ COMPETENCIES } & RII & RANK \\
\hline Teamwork & 0.871 & 1 \\
\hline Interdisciplinary skills & 0.783 & 2 \\
\hline Diversity skills & 0.770 & 3 \\
\hline
\end{tabular}

\section{SELF-MANAGEMENT GROUP}

The self-management group has four competencies, namely, self-management, info-management, managing development, and managing communications. The RII and the ranking of the self-management competencies are shown in Table 4 . The results indicated that the most important competency in this group was the self-management competency with $0.875 \mathrm{RII}$, followed by info-management and managing development with 0.852 and 0.841 RII indices, respectively. The least important competency was managing communications with 0.812 RII. Same results were found in Australia by Male et al. (2011), who found that the self-management group was considered the third most important competence required for engineers. 
Tab. 4. Ranking and RII for self-management group

\begin{tabular}{|l|c|c|}
\hline \multicolumn{1}{|c|}{ COMPETENCIES } & RII & RANK \\
\hline Self-management & 0.875 & 1 \\
\hline Info-management & 0.852 & 2 \\
\hline Managing development & 0.841 & 3 \\
\hline Managing communications & 0.812 & 4 \\
\hline
\end{tabular}

\section{ProfessionAlisM GROUP}

The professionalism group has six competencies, namely, honesty, commitment, demeanour, self-motivation, loyalty and concern for others. The results are shown in Table 5. According to the results, the most important competency in the professionalism group was honesty with $0.931 \mathrm{RII}$, followed by commitment with 0.923 RII. The least important competencies in this group were loyalty and concern for others with 0.871 and 0.833 RII indices, respectively. High importance ratings for the professionalism competency group were consistent with a previous study conducted in the US (Brumm et al., 2006), which included the professional impact competency in the proposed lowa State University (ISU) workplace competencies, and the study by Male et al. (2001) in Australia.

Tab. 5. Ranking and RII for professionalism group

\begin{tabular}{|l|c|c|}
\hline \multicolumn{1}{|c|}{ COMPETENCIES } & RII & RANK \\
\hline Honesty & 0.931 & 1 \\
\hline Commitment & 0.923 & 2 \\
\hline Demeanour & 0.888 & 3 \\
\hline Self-motivation & 0.874 & 4 \\
\hline Loyalty & 0.871 & 5 \\
\hline Concern for others & 0.833 & 6 \\
\hline
\end{tabular}

\section{Creativity/Problem-SOlving Group}

The creativity/problem-solving group contains five competencies, namely, problem-solving, creativity, info-sourcing, critical thinking, and embracing change. The results are shown in Table 6. According to respondents, is the most important was problem-solving competency with 0.929 RII, followed by creativity and sourcing info with 0.854 and 0.799 RII indices, respectively. The least important communication competency was embracing change with 0.777 RII. Creativity/problem-solving group was found important for engineers in the US study by Mier et al. (2000) and the study in Australia by Male et al. (2011). Both studies included five competencies in this group. Moreover, in the SPINE study (2002), which covered all Europe, the study found problem-solving skill as the most important skill for professors, engineers, and managers.

Tab. 6. Ranking and RII for creativity/problem-solving group

\begin{tabular}{|l|c|c|}
\hline \multicolumn{1}{|c|}{ COMPETENCIES } & RII & RANK \\
\hline Problem-solving & 0.929 & 1 \\
\hline Creativity & 0.854 & 2 \\
\hline Sourcing info & 0.799 & 3 \\
\hline Critical thinking & 0.778 & 4 \\
\hline Embracing change & 0.777 & 5 \\
\hline
\end{tabular}

\section{MANAGEMENT/LEADERSHIP GROUP}

The management/leadership group comprises nine competencies. The competencies and their ranking are shown in Table 7. The results demonstrate that focus was the most important competency in this group with $0.909 \mathrm{RII}$, followed by managing with 0.896 RII. Least important competencies were workplace politics and risk-taking with 0.809 and 0.664 RII indices, respectively. These results correspond with the findings of the Australian study by Male et al. (2011), which considered these competencies as important and required for engineers.

Tab. 7. Ranking and RII for management/leadership group

\begin{tabular}{|l|c|c|}
\hline \multicolumn{1}{|c|}{ COMPETENCIES } & RII & RANK \\
\hline Focus & 0.909 & 1 \\
\hline Managing & 0.896 & 2 \\
\hline Decision-making & 0.894 & 3 \\
\hline Leading & 0.893 & 4 \\
\hline Supervising & 0.884 & 5 \\
\hline Meeting skills & 0.877 & 6 \\
\hline Coordinating & 0.869 & 7 \\
\hline Workplace politics & 0.809 & 8 \\
\hline Risk-taking & 0.664 & 9 \\
\hline
\end{tabular}

\section{ENGINEERING BUSINESS GROUP}

The engineering business group contains only two competencies, namely, liability with 0.93 RII and crossfunction familiarity with 0.824 RII. Results are shown in Table 8. The results are consistent with Male et al. (2011) and Nguyen et al. (1998), who found that engineering business practice is one of the most important competencies required by engineers in Australia. Also, the study by Brumm et al. (2006) included the customer focus competency in the Iowa State University (ISU) workplace competencies. 
Tab. 8. Ranking and RII for engineering business group

\begin{tabular}{|l|c|c|}
\hline \multicolumn{1}{|c|}{ COMPETENCIES } & RII & RANK \\
\hline Liability & 0.930 & 1 \\
\hline Cross-function familiarity & 0.824 & 2 \\
\hline
\end{tabular}

\section{Practical engineering group}

The practical engineering group contains four competencies, including integrated design, reliability, manufacturability, and maintainability. The results are shown in Table 9. On the top of the list is the integrated design competency with $0.892 \mathrm{RII}$, followed by reliability, manufacturability and maintainability with indices of $0.879,0.833$ and 0.814 , respectively. Nguyen et al. (1998) found technical knowledge and skills as the most important generic skills and attributes for academics, the industry, and students. Also, the results were consistent with a previous study conducted in the US (Brumm et al., 2006), which included the engineering and general knowledge competency in the Iowa State University workplace competencies. Furthermore, the SPINE study (2002) found practical engineering experience competency as one of the important skills for professors, engineers, and managers in Europe.

Tab. 9. Ranking and RII for the practical engineering group

\begin{tabular}{|l|c|c|}
\hline \multicolumn{1}{|c|}{ COMPETENCIES } & RII & RANK \\
\hline Integrated design & 0.892 & 1 \\
\hline Reliability & 0.879 & 2 \\
\hline Manufacturability & 0.833 & 3 \\
\hline Maintainability & 0.814 & 4 \\
\hline
\end{tabular}

\section{INNOVATION GROUP}

The innovation group covers three competencies, namely, networking, entrepreneurship, and marketing. The results are shown in Table 10. The results revealed that networking competency had the highest RII 0.879, followed by entrepreneurship and marketing with 0.841 and 0.734 RII indices, respectively. The results were consistent with findings on an earlier study conducted in Australia (Male et al., 2011), the study by Spinks et al. (2006) in the UK, and a study made in the US (Brumm et al., 2006), which included the innova-

Tab. 10. Ranking and RII for the innovation group

\begin{tabular}{|l|c|c|}
\hline \multicolumn{1}{|c|}{ COMPETENCIES } & RII & RANK \\
\hline Networking & 0.879 & 1 \\
\hline Entrepreneurship & 0.841 & 2 \\
\hline Marketing & 0.734 & 3 \\
\hline
\end{tabular}

tion competency in the Iowa State University (ISU) workplace competencies.

\section{CONTEXTUAL RESPONSIBILITIES GROUP}

This group has four competencies, namely, safety, sustainability, community and social context. The results provided in Table 11 demonstrate that safety sustainability competencies have 0.927 and $0.863 \mathrm{RII}$ indices, but the community and social context competencies have almost the same RII 0.793 . These results are consistent with findings of the study conducted in the US (Brumm et al., 2006), which included the cultural adaptability competency in the proposed Iowa State University (ISU) workplace competencies. Also, the results are in line with findings by Male et al. (2011) and Nguyen et al. (1998), who found that contextual responsibility was one of the important competencies required by engineers in Australia.

Tab. 11. Ranking and RII for contextual responsibilities group

\begin{tabular}{|l|c|c|}
\hline \multicolumn{1}{|c|}{ COMPETENCIES } & RII & RANK \\
\hline Safety & 0.927 & 1 \\
\hline Sustainability & 0.863 & 2 \\
\hline Community & 0.793 & 3 \\
\hline Social context & 0.792 & 4 \\
\hline
\end{tabular}

\section{APPLYING TECHNICAL THEORY GROUP}

The applying technical theory group comprises four competencies. The competencies and their ranking are shown in Table 12. The results demonstrate that research competency is the most important one in this group with $0.827 \mathrm{RII}$, followed by 3D skills with 0.766 RII. The least important competency is theory with 0.676 RII. These results are in the same line with findings by Male et al. (2011) and Nguyen et al. (1998), who considered technical knowledge as the most important generic attribute required for engineers in Australia by academics, the industry, and students. Also, the results are consistent with a previous study conducted in the US (Brumm et al., 2006), which

Tab. 12. Ranking and RII for applying technical theory group

\begin{tabular}{|l|c|c|}
\hline \multicolumn{1}{|c|}{ COMPETENCIES } & RII & RANK \\
\hline Research & 0.827 & 1 \\
\hline 3D skills & 0.766 & 2 \\
\hline Modelling & 0.679 & 3 \\
\hline Theory & 0.676 & 4 \\
\hline
\end{tabular}


included the general knowledge competency in the Iowa State University (ISU) workplace competencies.

\section{RANKING AND RII FOR COMPE- TENCY GROUPS}

Once the RII indices are found, and the ranking of competencies in each group is completed, the next step is to organise eleven groups according to the RII. This was done by averaging the RII indices of the competencies in each group. Results are shown in Table 13 and Fig. 1. According to the results, ten competency groups have over $0.8 \mathrm{RII}$, which indicates that fresh engineering graduates rated these competencies as very important for their future career. This result is in

Tab. 13. Ranking and RII of competency groups expected to be required for fresh engineering graduates

\begin{tabular}{|l|c|c|}
\hline \multicolumn{1}{|c|}{ NAME OF GROUP } & RII & RANK \\
\hline Professionalism & 0.886 & 1 \\
\hline Engineering business & 0.877 & 2 \\
\hline Communication & 0.877 & 3 \\
\hline Management/leadership & 0.855 & 4 \\
\hline Practical engineering & 0.854 & 5 \\
\hline Self-management & 0.845 & 6 \\
\hline Contextual responsibilities & 0.843 & 7 \\
\hline Creativity/problem-solving & 0.827 & 8 \\
\hline Innovation & 0.818 & 9 \\
\hline Working in diverse teams & 0.808 & 10 \\
\hline Applying technical theory & 0.737 & 11 \\
\hline
\end{tabular}

line with findings by Male et al. 2011, who found that ten out of 11 groups had a factor of importance rating above three (with 1 for not needed and 5 - critically needed).

The high rating for professionalism ( $\mathrm{RII}=0.886$ ), which is attitudinal, is consistent with findings of earlier studies conducted in the US and Australia. This study broadly confirmed the results of the studies made in Australia. This group of competencies includes honesty, commitment, demeanour, self-motivation, loyalty, and concern for others.

On the other hand, the least important competency group is applying technical theory with 0.737 RII. This result is exactly in line with findings by Male et al. (2011) who concluded that relatively low ratings of importance for the most technical items were consistent with studies concentrating on the competencies required for engineering work. In their survey, Spinks et al. (2006) found that employers considered theoretical understanding to be relatively low as a skill that their graduates needed over the next ten years.

In spite of the moderately low ratings of technical competencies, they were amongst the competencies identified as generic for fresh engineering graduates. Male et al. (2011) promoted the prominence of technical competencies in the accreditation criteria that protect the society from potentially incompetent graduates of engineering study programmes.

To sum up, the identified technical and non-technical competencies include similar attitudes to those demonstrated by earlier studies conducted in the United States and Europe. As technical competencies,

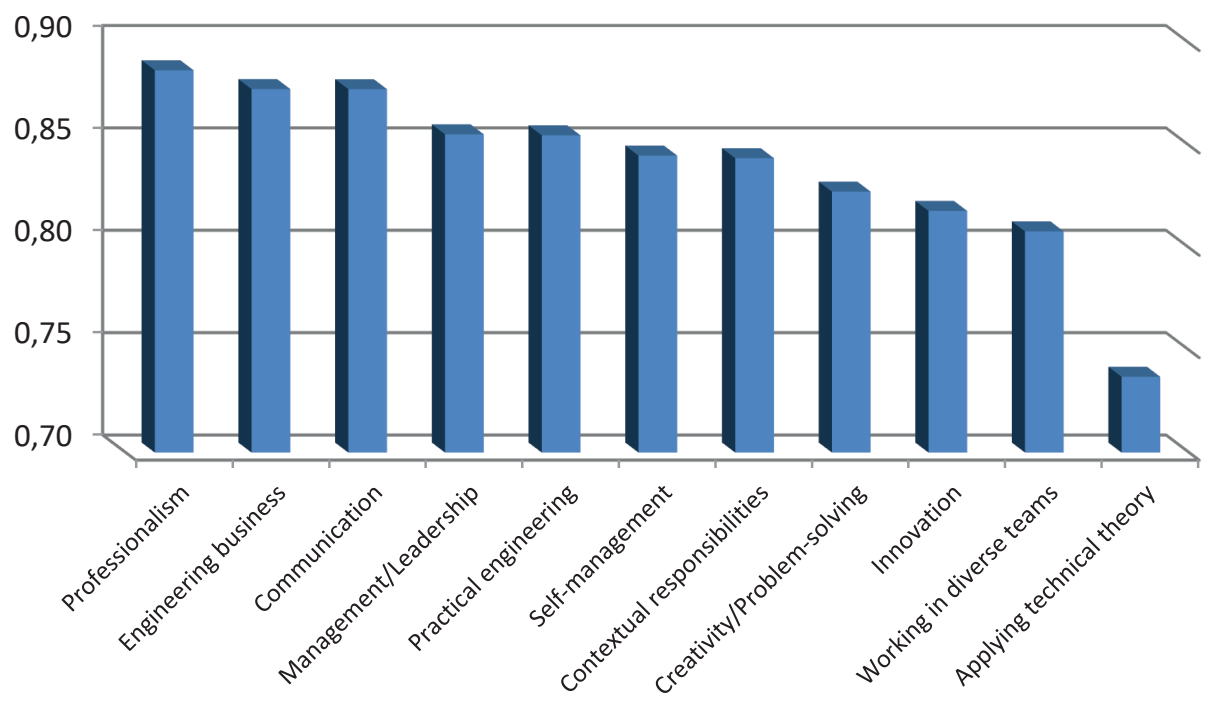

Fig. 1. Ranking and RII for competency groups expected to be required for fresh engineering graduates 
non-technical competencies and attitudes were deemed relevant.

\section{CONCLUSIONS}

As discussed previously, a major driver of the current accreditation requirements is to broaden the programme beyond the academic emphasis, including communication collaboration, ethics, social and environmental concerns. The results of this study support such development.

The eleven empirically defined competency factors are ideal to be used as part of the assessment and development of Jordanian engineering study programmes. Proof that graduates possess these competence factors will imply that the competencies required for engineering work are being established in the engineering education system.

The engineering competencies in the Jordanian engineering education sector could be summarised into two groups (non-technical and attitudinal). These competencies must be developed as well as others, identified in this research. Many educators recognise that development requires teaching and evaluation methods outside conventional seminars, tutorials, and laboratory sessions (Cameron, 2009). In terms of teaching settings, problem- or project-based learning provides opportunities to develop all groups of competencies, particularly interdisciplinary competencies (Kolmos, 1996). Cultural change is also necessary to raise the low status of technical competencies among engineering academics (Florman, 1997).

Training in engineering skills can be supplemented with business teaching in engineering. Also, cooperation between engineers and business academics must be explored. Furthermore, these efforts have the potential to ensure the international mobility of graduates from engineering study programmes, especially in the Middle East.

This study empirically identified the following 11 competency groups required for fresh engineering graduates, namely, professionalism, engineering business, communication, management/leadership, practical engineering, self-management, contextual responsibilities, creativity/problem-solving, innovation, working in diverse teams, applying technical theory. Non-technical and attitudinal competencies were assessed as important by engineers, which was consistent with earlier studies conducted in Europe and the US. This result supports the developments aiming to improve engineering curricula beyond technical skills in programme accreditation in Jordan and globally.
According to the results of this study, teamwork, management, communication, personal/attitudinal skills, problem-solving and the ability to learn were rated as highly significant. The competencies were established as essential by this research as well as verified by earlier studies.

More studies with other populations of engineers across Jordan and not only Amman would be useful to test the generalisability of results.

\section{LITERATURE}

ABET, (2008). Criteria for accrediting engineering programs, effective for evaluations during the 2009-2010 accreditation cycle. Baltimore, United States: Accreditation Board for Engineering and Technology.

Barlett, J. E., Kotrlik, J. W., \& Higgins, C. C. (2001). Organizational research: determining appropriate sample size in survey research. Information Technology, Learning, and Performance Journal, 19(1), 43-50.

Barrie, S.C., (2006). Understanding what we mean by the generic attributes of graduates. Higher Education, 51(2), 215-241.

Besterfield-Sacre, M. et al. (2000). Defining the outcomes: a framework for EC-2000. IEEE Transactions on Engineering Education, 43(2), 100-110. doi: $10.1109 / 13.848060$

Billing, D. (2003). Generic cognitive abilities in higher education: an international analysis of skills sought by stakeholders. Compare, 33(3), 335-350.

Bodmer, C., Leu, A., Mira, L., \& Rütter, H. (2002). Successful Practices in International Engineering Education. SPINE final report, Benchmarking Study, Zurich. Initial partners: Engineers Shape our Future, Zurich, and Rat der Eidgenössischen Technischen Hochschulen (ETH-Rat).

Boyatzis, R. E. (1982). The Competent Manager: A Model for Effective Performance. New York, United States: John Wiley.

Brumm, T. J., Hanneman, L. F., \& Mickelson, S. K. (2006). Assessing and developing program outcomes through workplace competencies. International Journal of Engineering Education, 22(1), 123.

Budiman, A., Suyanto, W., \& Efendi, Y. (2020). Mapping graduate learning competencies of the automotive engineering education. Journal of Physics: Conference Series, 1446(1), 012035.

Cheetham, G., \& Chivers, G. (1996). Towards a holistic model of professional competence. Journal of European Industrial Training, 20(5), 20-30.

CIOB (1996). Code of practice for project management for construction and development. The Chartered Institute Of Building, 2nd Ed. West Sussex, United Kingdom: Willy-Blackwell.

Daniel, K., \& Robert, K. (1966). The Social Psychology of Organizations. New York, United States: John Wiley.

Dante, G., \& Ignacio, D. R. (2012). Professional competences: a classification of international models. Procedia, 46, 1290-1296. 
EA (2005a). Engineers Australia national generic competency standards - stage 1 competency standards for professional engineers. Barton, ACT: Engineers Australia, P05.

EA (2005b). Engineers Australia policy on accreditation of professional engineering programs. Barton, ACT: Engineers Australia, P02.

ENAEE (2008). EUR-ACE framework standards for the accreditation of engineering programmes. Brussels: European Network for Accreditation of Engineering Education.

Ferguson, C. (2006). Defining the Australian mechanical engineer. European Journal of Engineering Education, 31(4), 471-485.

Florman, S. (1997). Non-technical studies for engineers: the challenge of relevance. European Journal of Engineering Education, 22(3), 249-258.

Hogg, B. (1993). European managerial competences. European Business Review, 93(2), 21-6.

Hornby, D., \& Thomas, R. (1989). Toward a Better Standard of Management. Personnel Management, 21(1), 52-55.

IPMA (2006). International Competence Baseline, International Project Management Association. Retrieved from: http://www.ipma.ch/certification.html

Kinkel, S., Schemmann, B., \& Lichtner, R. (2017). Critical competencies for the innovativeness of value creation champions: Identifying challenges and workintegrated solutions. Procedia Manufacturing, 9, 323330.

Kolmos, A. (1996). Reflections on project work and problem-based learning. European Journal for Engineering Education, 21(2), 141-148.

Male, S. A., Bush, M. B., \& Chapman, E. S. (2011). An Australian study of generic competencies required by engineers. European Journal of Engineering Education, 36(2), 151-163. doi: 10.1080/03043797.2011.569703

McClelland D. C. (1973). Testing for Competence Rather Than for Intelligence. American Psychologist, 28(1), 1-14.

Meier, R. L., Williams, M. R., \& Humphreys, M. A. (2000). Refocusing our efforts: assessing non-technical competency gaps. Journal of Engineering Education, 89(3), 377-385.

Ministry of Higher Education \& Scientific Research. Retrieved from http://www.mohe.gov.jo/ar/Pages/StateUniversities.aspx

Mutiara, M., R., Primiana, I., Joeliaty, J., \& Cahyandito, M. F. (2019). Exploring cultural orientation on the entrepreneur competencies in the globalization era. Business: Theory and Practice, 20, 379-390. doi: $10.3846 /$ btp. 2019.36

Nguyen, D. Q. (1998). The essential skills and attributes of an engineer: A comparative study of academics, industry personnel and engineering students. Global Journal of Engineering Education, 2(1), 65-75.

OECD (2002). Definition and selection of competencies (DeSeCo) theoretical and conceptual foundations: Strategy paper. Paris, France: Organization for Economic Co-Operation and Development.
Omran, A., \& Suleiman, A. (2017). Identifying the Competence Components of the Construction Project Managers in the Palestinian Construction Industry. The Engineering Project Organization Journal, 7(2).

QAA (2006). Subject benchmarking statement: Engineering. Gloucester: The Quality Assurance Agency for Higher Education.

Rychen, D. S., \& Salganik, L. H. (2003). Key competencies for a successful life and a well-functioning society. Cambridge, United States: Hogrefe and Huber.

Šafránková, J. M., \& Šikýř, M. (2018). Responsibilities and competencies in personnel management at Czech schools. Oeconomia Copernicana, 9(3), 529-543. doi: 10.24136/oc.2018.027

Schippmann, J. S., Ash, R. A., Battista, M., Carr, L., Eyde, L. D., Hesketh, B., Kehoe, J. Pearlman, K., \& Sanchez, I. (2000). The practice of competency modeling. Personnel Psychology, 53, 703-740.

Scott, G., \& Yates, K. W. (2002). Using successful graduates to improve the quality of undergraduate engineering programmes. European Journal of Engineering Education, 27(4), 363-378.

Solesvik, M. Z. (2019). Entrepreneurial competencies and intentions: the role of higher education. Forum Scientiae Oeconomia, 7(1), 9-23. doi: 23762/FSO_VOL7_ NO1_1

Spinks, N., Silburn, N., \& Birchall, D. (2006). Educating engineers for the 21st century: The industry view. London, United Kingdom: The Royal Academy of Engineering.

Tucker, S., \& Cofsky, K. (1994). Competency-Based Pay on a Banding Platform. ACA Journal, 3(1), 30-45.

Vichita, V., \& Jintawee, T. (2007). Competency Requirements for Effective Job Performance in the Thai Public Sector. Contemporary Management Research, 3(1), 45-70. 